\title{
An Exploratory Study of Social Game by Flow Theory and Social Network Theory
}

\author{
Chun-Hsiung Huang ${ }^{1}$ \\ Dept. of Information Management, National Yunlin \\ University of Science and Technology, Taiwan, R.O.C. \\ Dept. of Digital Content Design, Ling Tung University, \\ Taichung, Taiwan, R.O.C. \\ huangch@teamail.ltu.edu.tw
}

\author{
$\mathrm{Mu}-\mathrm{Chiun} \mathrm{Hsu}^{2}$ \\ Dept. of Information Management, National Yunlin \\ University of Science and Technology, Taiwan, R.O.C. \\ Huan-Ming Chuang ${ }^{3}$ \\ Dept. of Information Management, National Yunlin \\ University of Science and Technology, Taiwan, R.O.C.
}

\begin{abstract}
Facebook triggered a popular trend in Taiwan because it changed users' Internet social cognition. Before this, the Internet users interact with others only by search engines, online advertising, e-mails or blogs. Network users are fully immersed in Facebook social network as in a real interpersonal network platform, which triggers their intended use. Every Internet user initially acts as a self-centered base. Through a social network as Facebook, it allows one to quickly connect related users in a short time and contact them extensively to the entire internet world. This study intends to explore the possible impact of the immersed phenomenon which often occurs in the games, as well as, from external factor of social network and internal factor of flow theory to discuss the possible reason for users to play the Facebook games. Through answering online questionnaire in Chinese by Taiwanese Facebook users, the researchers collect 104 valid samples. By using regression analysis, the results display that social network and the intended use in a negative relationship. The immersed phenomenon has a positive effect on user intention in Facebook games. The authors assumed that Facebook game players may not have intention of social, but only want to play the games in Facebook social network and be fully emerged in game playing. Therefore, the major factors enabling users' psychological satisfaction in Facebook game playing will be critical in game design applications.
\end{abstract}

Keywords-social games; flow theory; social network theory; user intention

\section{INTRODUCTION}

The fast development of World Wide Web becomes the major channel for modern people's common interaction. In Social Network Sites, it uses many interactive functions such as chatting, text, video and sound mails, sharing files, blogging, and attending meetings and discussions. Facebook connects everyone's daily life. Social Networking's pervasive growth continues to spread in popularity and importance in all segments of the population, across industries and countries. The importance and growing attention to social networks can be seen in marketing, health, education, economics, and throughout a variety of other industries. Shipps and Phillips [1] focuses on interactivity and its role in user satisfaction with a social network site.

The social network games in Facebook have the very possibility of becoming a brand new interacting tool. As the population of Facebook users, the social network games may become the brand new interactive social tool. According to the study of Cole and Griffiths [2], about $26 \%$ of players will play games with real friends and family members. The game is a social behavior. The players interact with others, make friends, and even get married. Internet game became a part of daily life of people. The friendship happened in internet games become real social relationship in real life.

Modern people often indulge in certain activities in order to pursue happiness and achievement and enter in a state of ecstasy. When a person involves in an activity, challenged by their skills limits, will be immerged into it and looking for and enjoy the fun created by playing, thus creating a phenomenon of "immersion". Emotional experience from individuals interacting with the game environment arises from the immersion experience in human-computer interaction. Flow Theory was used to manipulate the level of challenge and indirectly the level of perceived skill to create three design conditions: Boredom, Flow, and Frustration. These performance measures also provide useful data that can be combined with self-report data to produce high measurement diagnosticity and sensitivity [3].

The purpose of this study is to explore the factor of increasing population of Facebook users. Facebook games may have a positive influence on it. The authors define this as external factor. This paper also investigated in Facebook games if the players be fully emerged in games. For this internal reason, the players choose this internet social network siteFacebook.

\section{REVIEWED LITERATURE}

\section{A. Flow Theory}

Csikszentmihalyi [4] pointed out that, when individuals concentrate on certain activities, will enter some unique 
patterns of experience, including narrowing the perceptual attention to filter all irrelevant feelings and thoughts, loss of consciousness, and will reach a state of ecstasy. When people are engaged in activities to concentrate and ignore the surrounding environment, that is, to enter a state of immersion. This immersive experience gives people the feelings of pleasure and satisfaction; they repeat such an activity to attain the same experience of enjoyment and pleasure.

Ghani and Deshpande [5] claimed there are two main features of immersion: fully concentrated (concentration) on and enjoy guided activities (enjoyment). When individuals totally engaged in their activities, they will be fully concentrated on and filter out all irrelevant perception and immersed into a state of "immersion". The immersive experience will allow users to put more emphasis on process rather than result [6]. When the users pursue particular goal under subjective consciousness, and the users' ability highly matches with the challenges, they are easily immersed into the "immersion" [7].

Skill and challenges are two important factors in flow theory. These two must be balanced and driven by oneself toward a higher level of complexity. Fully involved in activities, individuals may complete the impossible task. But the person cannot perceive that the challenges from the activities already advance the individual abilities to be more committed to learning new skills. In the meantime, it will ensure the self-assertiveness [8-9]. We can know the "immersion" is when an individual refers to a completely immersed in an activity due to their own interests, and thus completely integrated into the activities, focused on what they are working on and unfelt the outside world. Immersion is a subjective and temporary experience. One of the reason why people are willing to continue certain activities [10-11].

\section{B. Social Network Theory}

Wellman [12] stated that the social network is relatively stable system constituted by social relations between certain individuals, that is, the "Network" as a series of social contact or social relationships as links of actors. With the continuous expansion of the range of applications, the concept of social network has gone beyond the scope of interpersonal relationships. The network of actors can be an individual or a collection of units, such as family, departments, organizations, etc.

Social network theory defines that in a network, the number of social capital of an organization or individual determines its position in the network structure. Social network, from the collective point of view of social capital, provides support for each member to win the certificate of prestigious certificate and exists as a form of a network relationship. In social network studies, the actors or the nodes have been variously defined as individuals, groups, or even countries. The relationship is a flow of resources that can be material or non-material [13]. The resources might include social support, emotional support, companionship, time, information, expertise, money, business transactions, shared activity, and so on.

The emphasis on interpersonal network structure offers the advantages of information and resources to its organizations and individuals. The direct links between the network structure and individuals exclude others. The Internet as a whole appears as a structural hole. If the network and individuals lack direct connection and only linked through the third party. Then this third party occupies a structural hole. Therefore, this structural hole will possess the information superiority and excellent control.

\section{Intention to Use}

Chun-xing Zhang [14] that intention is a state that an individual driven to do certain acts to pursue the goal or to assist the individual to select the target and internalize its behavior toward this goal. It promotes the internal driving force behind the idea, which leads to personal behavior, and to maintain the behavior, to guide individuals to meet a certain target process. This is called "intention". The intention and need are inseparable. When the idea of intention appears, the need will be met. Their behavior will be affected by personal, social, and cultural influences, and thus the desire arises. When the goal is reached, the desire is naturally quelled. This is the development of intention.

Fishbein and Ajzen [15] thought that behavioral intention is the "subjective probability" of an individual desire to engage in a particular behavior. That is, when a person wants to take a particular action, the intention will arise before determine whether to take the action. Davis [16] in the Technology Acceptance Model pointed out, "the use of state level" is influenced by "perceived usefulness" and "perceived ease of use"; while "behavior intention" is influenced by by "the user attitude" and "perceived usefulness"; The user's "behavior intention" has direct impact on "use behavior". Hubona and Geitz [17] pointed out that the attitude is the main reason of the technology acceptance model affecting belief, and then attitude will affect the user's intention of use. Morris [18] also pointed out that perceived usefulness has a positive effect on the use of attitude, and the cognitive usefulness and attitude has positive influence on the use of intention. Intention to use has a positive influence on actual use behavior.

\section{Methodology}

\section{A. Research structure}

The purpose of this study is to adopt the social network theory and flow theory to explore if Facebook social network game will increase the user's intention to use, and then expand the influence of the social networking site as Facebook. The $\mathrm{H} 1-\mathrm{H} 2$ hypothesis of this study derived as follows:

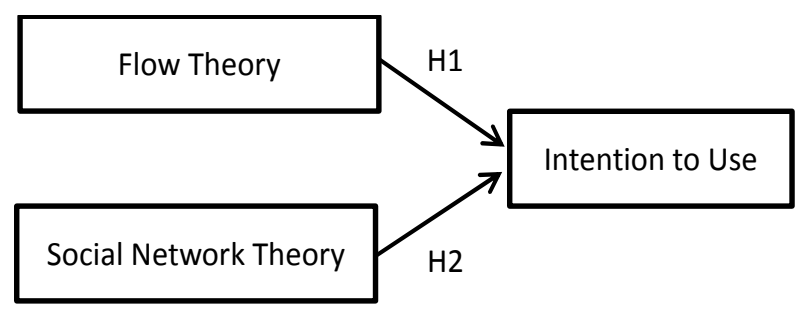

Fig. 1. Research Mode 


\section{B. Hypotheses}

Immersion is when an individual is fully immersed in an activity due to their own interests, and thus completely integrated into the activities and unfelt to the outside world. This study hypothesized that the users will enjoy in interested activities for the reason of self-pursuit.

The hypotheses H1: flow theory has a positive influence on the intention to use.

The related elements of social network theory explain the actors and social attachment through the linked density, strength, symmetry, and scale to describe specific behaviors and processes. Therefore, this study concluded that the users will inspire related users to engage the same activities and motivate them to use.

The hypotheses H2: the social network has a positive influence on the intention to use.

\section{Research Design}

This study investigated the factors of the Facebook social networking site and set up a social network and flow experience to analyze the relationship between these two factors and the intention to use. This study integrates the related research questionnaire design literature in the past with reliability and validity to arrange the most applicable questions. Before the actual questionnaire testing, there is pre-test to clearly understand the meaning of the questions and promote the validity and also to appropriately measure the research variables and analyze the reliability. The study object is a virtual community. The questionnaire is sent out by using Internet to the users of Facebook social network games.

\section{RESULTS AND DISCUSSIONS}

\section{A. Descriptive Analysis}

Samples collected in this study are in a manner of sending out questionnaire over the convenience of internet. First is to use Google to establish a questionnaire and it is distributed to the major forums and researchers' Facebook accounts. The returned samples were collected about in four weeks and the total sample number is 104 .

\section{B. Reliability and Validity Analysis}

The three variables of immersive experience, social network, and intention are used to construct a questionnaire of 23 questions, mainly based on the related literatures and then the questionnaire was pretested by five persons, and then put out on internet after modifications. The questionnaire has a certain degree of validity. The two dimensions of Cronbach's alpha are listed in Table I:
TABLE I. CRONBACH'S $\alpha$ OF EACH DIMENSION

\begin{tabular}{|c|l|l|}
\hline Dimensions & \multicolumn{1}{|c|}{ Cronbach's $\alpha$} & \multicolumn{1}{c|}{ Results } \\
\hline Flow & 0.748 & Over 0.7: passed \\
\hline Social network & 0.875 & Over 0.7: passed \\
\hline Intention to use & 0.879 & Over 0.7: passed \\
\hline Total results & 0.874 & Over 0.7: passed \\
\hline
\end{tabular}

\section{Correlation and Regression Analysis}

Before performing regression to understand the relationship between dimensions, whether the the correlation dimension should be explored. Through the Pearson correlation analysis of various dimensions are listed in Table II:

TABLE II. PEARSON CORRELATION ANALYSIS TABLE

\begin{tabular}{|c|l|l|l|}
\hline & Flow & \multicolumn{1}{|c|}{ Social network } & Intention to use \\
\hline Flow & 1 & & \\
\hline Social network & $0.424 * * *$ & 1 & \\
\hline Intention to use & $0.632 * * *$ & $0.468 * * *$ & 1 \\
\hline \multicolumn{2}{|r}{$\quad * * * \mathrm{P}<0.01$, two-tailed test }
\end{tabular}

Resulting there is significant relationships between dimensions. The lowest is between flow and social network (0.424) and highest is between flow and intention to use (0.632). The value of VIF should be as small as possible, preferably no more than 10 . Regarding collinearity, the VIF value of each dimension is lower than 10. The highest is 2.147. The collinearity problems are not serious. Therefore, this research continues to explore multiple regression analysis hypothesis. The final results are presented in Table III:

TABLE III. REGRESSION ANALYSIS

\begin{tabular}{|c|c|c|c|}
\hline $\begin{array}{c}\text { Dependent } \\
\text { variable }\end{array}$ & $\begin{array}{c}\text { Independent } \\
\text { variable }\end{array}$ & Beta Value & $\mathbf{T}$ \\
\hline \multirow{2}{*}{ Intention to use } & Flow & $\mathbf{0 . 7 4 0 * * *}$ & $\mathbf{7 . 5 9 4}$ \\
\cline { 2 - 4 } & Social network & $-\mathbf{0 . 2 1 4}$ & $\mathbf{- 2 . 3 5 8}$ \\
\hline \multicolumn{2}{|c|}{$\mathbf{F}=\mathbf{2 9 . 2 4 * * *}$} \\
\hline
\end{tabular}

\section{CONCLUSION}

\section{A. Research Conclusion}

The results of the testing show that flow is an important influential factor of intention to use. In our study proved the reason is to plays Facebook games to pursue the psychological satisfaction. One is fully immersed in the situation and pursues the particular goals. Another negative result is in the relationship between social network and intention to use. This study assumed that the users of social network site play the Facebook games, due to many familiar friends around you in the games, the intention to use decreases. Besides, the relationship shows positive influence between flow and intention to use. Flow influence the users absorbed in the 
Facebook games to challenge self limits. When the flow in intention to use is positive, the user's intention to use increases.

This study intends to assist the social network sites as the Facebook to design their social network games. The design should consider various principles of feeling of operating, difficulty of mission challenge, experience value attainment, and choice of comrades. This study discovered that the intention of use of playing games locates in users' psychological satisfaction.

\section{B. Limitation and Recommendation}

Due to the time, human resources, and financial factors, the authors suggest the following recommendations: 1 . The objects in this study are basically under the age 25 , limited in age ranges; 2 . The questionnaires are distributed over the internet platform. Most of the samples are users of internet. It's very easy to find the Facebook users; 3 . This study focuses on the Facebook games. It is recommended to use different web games for the future research. The different functional website may produce different results of social games influential factors.

\section{REFERENCES}

[1] B. Shipps and B. Phillips, "Social Networks, Interactivity and Satisfaction: Assessing Socio-Technical Behavioral Factors as an Extension to Technology Acceptance," Journal of Theoretical and Applied Electronic Commerce Research, vol. 8(1), pp. 35-52, 2013.

[2] H. Cole and M. Griffiths, "Social Interactions in Massively Multiplayer Online Role-Playing Gamers," CyberPsychology and Behavior, vol. 10(4), pp. 575-583, 2007.

[3] D. Sharek and E. Wiebe, "Using Flow Theory to Design Video Games as Experimental Stimuli," Proceedings of the Human Factors and Ergonomics Society Annual Meeting, vol. 55, pp. 1520- 1524, 2011.

[4] M. Csikszentmihalyi, Beyond Boredom and Anxiety. San Francisco : Jossey-Bass, 1975.
[5] A. J. Ghani and P. S. Deshpande, "Task Characteristics and the Experience of Optimal Flow in Human-Computer Interaction," The Journal of Psychology, vol. 128(4), pp. 381-391, 1994.

[6] G. Privette and C. M. Bundrick, "Measurement of Experience: Construct and Content Validity of the Experience Questionnaire," Perceptual and Motor Skills, vol. 65, pp. 315-332, 1987.

[7] P. T. Novak, L. D. hoffman, and Y. F. Yung, "Measuring the Customer Experience in Online Environments: A Structural Modeling Approach," Marketing Science, vol. 1 (19), pp. 28-29, 2000.

[8] M. Csikszentmihalyi and J. LeFevre, "Optimal Experience in Work and Leisure," Journal of Personality and Social Psychology, vol. 56 (5), pp. 815-822, 1989.

[9] D. L. Hoffman and T. P. Novak, "Marketing in Hypermedia ComputerMediated Environments: Conceptual Foundations," Journal of Marketing, vol. 60, pp. 50-68, 1996.

[10] M. Csikszentmihalyi, Flow : The Psychology of Optimal Experience, NewYork : Harper and Row, 1990.

[11] J. Webster, L. K. Trevino, and L. Ryan, "The Dimensionality and Correlates of Flow in Human Computer Interactions," Computers in Human Behavior, vol. 9 (4), pp. 411-426, 1993.

[12] B. Wellman, "Structural Analysis: From Method and Metaphor to Theory and Substance," in Social Structures: A Network Approach, Barry Wellman and S.D. Berkowitz, eds. Cambridge: Cambridge University Press, pp. 19-61, 1988

[13] S. Wasserman and K. Faust, Social Network Analysis: Methods and Applications, Cambridge, England: Cambridge University Press, 1994.

[14] Chun-xing Zhang, Educational Psychology. Taipei: Tung Wah Group, 1994.

[15] M. Fishbein and I. Ajzen, Belief, Attitude, Intention and Behavior: An Introduction to Theory and Research Reading, MA: Addison-Wesley, 1975.

[16] F. D. Davis, "Perceived Usefulness, Perceived Ease of Use, and User Acceptance of Information Technology," MIS Quarterly, vol. 13(3), pp. 319-340, 1989.

[17] G. S. Hubona and S. Geitz, "External Variables, Beliefs, Attitudes and Information Technology Usage Behavior," Proceedings of the Thirtieth Hwaii International Conference, vol. 3, pp. 21-28, 1997.

[18] M. G. Morris and A. Dillon, "How User Perceptions Influence Software Use," IEEE Software, vol. 14(4), pp. 58-65, 1997. 